\title{
Práticas sustentáveis nas pequenas propriedades de agricultura familiar: um estudo de caso
}

\author{
Sustainable practices in the small properties of family agriculture: a case study \\ Nilmar Sandro Kesseler', Yvelise Piccinin², Marivane Vestena Rossato³, Andrea Cristina Dörr', Luiz Antônio Rossi de Freitas ${ }^{5}$, \\ Alex Marin 6 \\ 1 2Graduando em Ciências Contábeis da Universidade Federal de Santa Maria, Bolsista FIPE/UFSM, Santa Maria, RS - Brasil \\ ${ }^{3}$ Professora Adjunta no Departamento de Ciências Contábeis da UFSM, Santa Maria, RS - Brasil \\ ${ }^{4}$ Professora Adjunta no Departamento de Ciências Econômicas da UFSM, Santa Maria, RS - Brasil \\ ${ }^{5}$ Professor Adjunto no Departamento de Ciências Contábeis da UFSM, Santa Maria, RS - Brasil \\ ${ }^{6}$ Graduando em Ciências Contábeis da Universidade Federal de Santa Maria, Santa Maria, RS - Brasil
}

\begin{abstract}
Resumo
Pela importância econômica e social bem como pela capacidade de impactar o meio ambiente pelas atividades de agricultura familiar exercida, insere-se a problemática deste estudo de quais as práticas adotadas pelos produtores rurais de agricultura familiar no município de Santa Maria/RS permitem evidenciar características de sustentabilidade. A partir da análise dessas práticas e da percepção dos produtores rurais quanto à legislação ambiental brasileira vigente, esses, apesar de considerarem a questão ambiental importante, não estão desenvolvendo suas atividades de maneira plenamente sustentável, visto que um de seus pilares, o ambiental, apresenta pontos a melhorar para o desenvolvimento harmônico com as variáveis social e econômica. Esse fator poderia ser obtido com a adequada destinação dos resíduos das propriedades. Tais resultados foram possíveis pela aplicação de um questionário aos produtores rurais de agricultura familiar do município de Santa Maria/RS.
\end{abstract}

Palavras-chave: Agricultura familiar. Sustentabilidade. Percepção ambiental. Legislação ambiental. Economia regional.

\begin{abstract}
Considering the economic and social importance, as well as by the ability to impact the environment through the use of natural resources, this study arises the problematic of which the practices adopted by the rural producers in the municipality of Santa Maria/RS allow to evidence characteristics of sustainability. From the analysis of these practices and perceptions of rural producers regarding the Brazilian environmental legislation in force, despite the importance of environmental issues, are not developing their activities in a fully sustainable way, considering that one of its pillars, the environmental, introduces areas for improvement with regards the harmony development with the social and economic variables. This factor could be obtained with appropriate waste disposal of the farms. Such results were made possible by the application of a questionnaire to rural producers agriculture in municipality of Santa Maria/RS.
\end{abstract}

Keywords: Family agriculture. Sustainable. Environmental perception. Environmental legislation. Regional economy. 


\section{INTRODUÇÃO}

A sustentabilidade aparece como uma necessidade em qualquer meio produtivo. Atualmente, com a preocupação ambiental e a preservação dos recursos naturais, todas as organizações precisam desenvolver medidas que, atendendo a legislação vigente, amenizem ou eliminem os efeitos gerados ou estimulados por seu processo produtivo ao meio ambiente e à sociedade. Estas práticas possibilitam a continuidade de suas atividades e a melhoria de sua imagem mercadológica como empreendimento sustentável.

O desenvolvimento econômico e social de regiões do meio rural através da utilização de solos agricultáveis, em qualquer lugar do mundo, deve prezar pela conservação do bioma nas relações com o mesmo. A agricultura, por se utilizar da capacidade produtiva dos recursos naturais, bem como por sua interação com o meio ambiente através da dispersão de resíduos, tanto físicos como químicos, possui grande potencial em influenciar os agentes naturais e, consequentemente, impactar os compartimentos ambientais. Além disso, é um importante agente econômico e social, tanto pela representatividade da produção de alimentos como também por ser o meio de subsistência de grande parte da população que desenvolve esta atividade na forma de produção familiar, os produtores de agricultura familiar.

No Brasil, $15,64 \%$ da população vive no meio rural. Já no Rio Grande do Sul, esta representatividade é de 14,9\% (IBGE, 2010). A maioria dos estabelecimentos rurais são de agricultura familiar, aproximadamente $84,4 \%$ a nível de Brasil e $85,75 \%$ no Rio Grande do Sul (IBGE, 2006), sendo esta a principal fonte de renda e subsistência das famílias que vivem neste meio. Apesar de ocupar apenas um quarto da área, a agricultura familiar responde por $38 \%$ do valor da produção (ou $\mathrm{R} \$ 54,4$ bilhões) deste total.

A partir disso, percebe-se a influência da agricultura no cenário nacional, seja pela representatividade econômica, pelos impactos ambientais que pode ocasionar e consequentes reflexos na sociedade. A sustentabilidade, pautada na interação harmônica destas três dimensões, aparece como condição essencial para um desenvolvimento que garanta continuidade ao atender às necessidades presentes e futuras da população que dependa deste meio. Isto justifica a importância de estudos que visem identificar quais medidas estão sendo adotadas e quais melhorias são pertinentes na busca do desenvolvimento sustentável.

No município de Santa Maria/RS, assim como no Brasil, a maior parte da população habita no meio urbano. A parcela que reside no meio rural distribui-se em nove distritos e sua configuração é predominantemente de agricultura familiar. É sabido que para se manter qualquer atividade com a garantia de sua continuidade, devem ser sempre observados os princípios do desenvolvimento sustentável, o qual consiste no atendimento das demandas econômicas, sem prejuízo às demandas sociais e àquelas as quais busquem a preservação do meio ambiente.

A partir disso, buscou-se verificar a seguinte questão problema: quais as práticas adotadas pelas propriedades rurais de agricultura familiar do município de Santa Maria/RS que permitem evidenciar características de sustentabilidade? Para a consecução desta, objetivou-se analisar a percepção dos produtores rurais quanto às práticas sustentáveis e à legislação ambiental brasileira, bem como a utilização de práticas rurais que evidenciam características de sustentabilidade.

Estudo semelhante foi realizado por Zancan et al. (2012), a fim de verificar a percepção ambiental dos gestores das agroindústrias do município de Santa Maria/RS, bem como as formas de destinação de resíduos adotadas por estas organizações com a finalidade de avaliar sua sustentabilidade.

O presente estudo está estruturado em cinco capítulos. Além desta introdução, aborda-se o referencial teórico, onde se encontram as teorias que serviram de suporte à análise dos resultados. Em seguida é apresentada a metodologia, que aborda as técnicas de pesquisa utilizadas e, na sequência, apresentam-se e discutem-se os resultados obtidos. Por fim, são expostas as considerações finais.

\section{REFERENCIAL TEÓRICO}

Esta seção fundamenta a pesquisa a partir da exposição dos conceitos sobre a agricultura familiar e a sustentabilidade, assim como sua importância para o meio rural.

\section{I Concepções da agricultura familiar}

A empresa rural, seja familiar ou patronal, é um organismo econômico e social que, integrando terra, capital, trabalho e demais recursos naturais, objetiva produzir bens e serviços na expectativa da geração de lucros de maneira sustentável. Michaud (1989) define a gestão agrícola como aquela que respeita os valores culturais do produtor rural, de sua família, das organizações e do meio ambiente, buscando a utilização racional dos fatores de produção. 
Buainain e Romeiro (2000) destacam que a agricultura familiar não se foca somente em um segmento, e sim, diversifica entre criação de animais, culturas agrícolas e transformações primárias, tanto para o consumo da família como para a comercialização, desenvolvendo, assim, sistemas complexos de produção.

Crepaldi (2005) discorda ao afirmar que o empresário rural está aos poucos diminuindo a variação de atividades em sua propriedade, dedicando-se àquelas nas quais possui mais experiência ou especializando-se para obter uma melhor qualidade no produto. Através disso, consegue-se um melhor preço no mercado e amplia-se a vantagem competitiva.

Conforme a Lei $\mathrm{n}^{\circ} .4 .504 / 64$, Art. $4^{\circ}$, Inciso II, considera-se Propriedade Familiar

o imóvel rural que, direta e pessoalmente explorado pelo agricultor e sua família, lhes absorva toda a força de trabalho, garantindo-lhes a subsistência e o progresso social e econômico, com área máxima fixada para cada região e tipo de exploração, e eventualmente trabalho com a ajuda de terceiros.

Para Wanderley (2009), agricultura familiar é aquela em que o trabalho de seus integrantes constitui um sistema de produção que supra as despesas da propriedade e garanta o sustento daquela entidade familiar. Dada sua importância, tem sido alvo de interesses a partir do estabelecimento de conceitos, princípios e instrumentos destinados à formulação de políticas públicas. $\mathrm{O}$ reconhecimento desta categoria encontra-se no Art. 3o da Lei n. ${ }^{\circ}$ 11.326, de 2006, que define:

[...] agricultor familiar e empreendedor familiar rural aquele que pratica atividades no meio rural, atendendo, simultaneamente, aos seguintes requisitos:

I - não detenha, a qualquer título, área maior do que 4 (quatro) módulos fiscais;

II - utilize predominantemente mão-de-obra da própria família nas atividades econômicas do seu estabelecimento ou empreendimento;

III - tenha percentual mínimo da renda familiar originada de atividades econômicas do seu estabelecimento ou empreendimento, na forma definida pelo Poder Executivo (Redação dada pela Lei n ${ }^{\circ} 12.512$, de 2011); $\mathrm{V}$ - dirija seu estabelecimento ou empreendimento com sua família.
No cenário atual, acompanha-se uma grande preocupação com a agricultura familiar e a melhoria da qualidade de vida das pessoas no campo. Políticas desenvolvidas pelo Estado para se alcançar estes objetivos são constatadas nos incentivos fiscais e programas governamentais, como por exemplo, o Pronaf (Programa de Fortalecimento da Agricultura Familiar), o Programa Mais Alimentos, entre outros.

\subsection{Sustentabilidade no meio rural}

As três dimensões que baseiam a sustentabilidade são englobadas no conceito do Triple Bottom Line, modelo internacionalmente aceito e reconhecido, que tem como base não somente o plano econômico, mas também os aspectos sociais e ambientais de forma integrada. A figura 1 ilustra a integração entre os pilares econômico, ambiental e social do desenvolvimento sustentável.

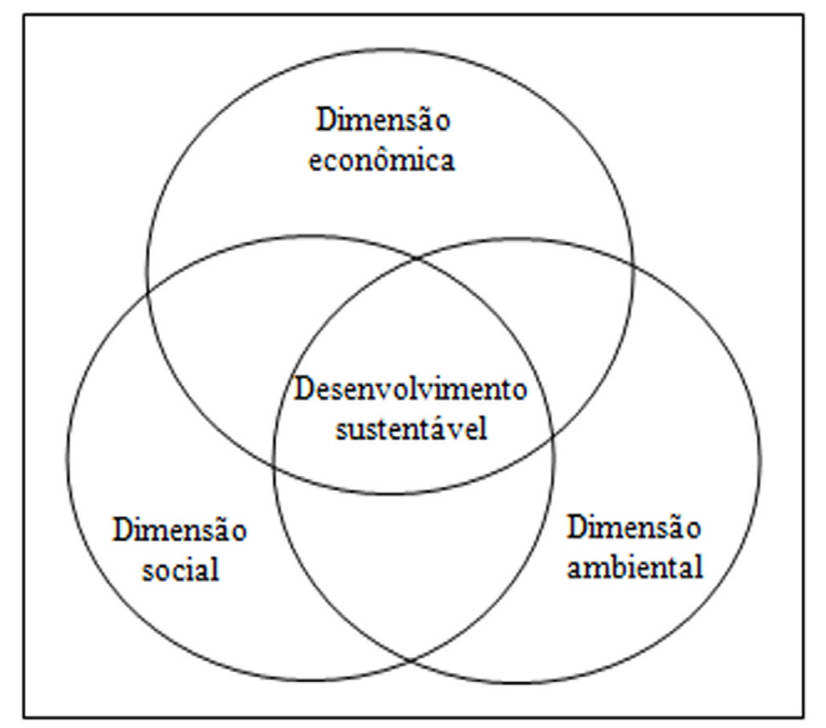

Figura 1 - Dimensões da sustentabilidade organizacional Fonte: adaptada de Barbieri e Cajazeira (2009, p. 70).

Berry e Rondinelli (1998) explicam que num primeiro momento as atividades ambientais servem para adequar o processo produtivo à legislação ambiental. Posteriormente, as organizações veem oportunidades a partir de projetos que agregam valor aos resíduos, pois isto acarreta a redução de custos, incremento nas receitas e melhoria na imagem das organizações.

O termo resíduo pode ser entendido, segundo Lima (1995) como toda e qualquer sobra resultante dos processos produtivos industriais e classifica-os em algumas categorias, quais sejam, resíduos considerados perigosos, potencialmente biodegradáveis e os considerados inertes e incombustíveis. No meio rural estes conceitos também 
são de fundamental aplicabilidade em busca de um desenvolvimento sustentável. Este ocorre no momento em que se proporciona o bem-estar das atuais sociedades, prezando pelo equilíbrio dos recursos e visando qualidade para as sociedades futuras.

Tinoco e Kraemer (2004, p. 31) definem desenvolvimento sustentável como "aquele que atende às necessidades do presente, sem comprometer a possibilidade de as gerações futuras atenderem as suas próprias necessidades". Os mesmos autores afirmam que uma atividade sustentável não pode ser praticada ou pensada em separado, porque está inter-relacionada ao desenvolvimento sustentável, dado que, apesar dos imprevistos que possam vir a ocorrer, ela tem o intuito de se manter por um longo período de tempo.

A preocupação com a adequada utilização dos recursos naturais exauríveis constitui uma das medidas fundamentais na busca do desenvolvimento sustentável. Segundo Afonso (2006, p. 11) a sustentabilidade

implica na manutenção quantitativa e qualitativa do estoque dos recursos ambientais, utilizando tais recursos sem danificar suas fontes ou limitar a capacidade de suprimento futuro, para que tanto as necessidades atuais quanto aquelas do futuro possam ser igualmente satisfeitas.

Para Buainain (2006, p. 47), a ideia de sustentabilidade tem "forte conteúdo ambiental e um apelo claro à preservação e à recuperação dos ecossistemas e dos recursos naturais". Este fato deve-se ao potencial que ações as quais denigrem o ambiente tem de impactar negativamente nas demais variáveis que compõem a sustentabilidade de forma direta ou indireta.

Paulus e Schlindwein (2001) complementam que ao se conceituar agricultura sustentável, a valorização das comunidades rurais em aspectos sociais, humanos e culturais nem sempre é contemplada. No entanto, não há dúvidas que a diversidade cultural é tão imprescindível quanto à biodiversidade vegetal e animal. Logo, a sustentabilidade integra além destes elementos, o fator econômico, que juntos compõem os três pilares na qual a sustentabilidade se apoia.

Petter (2002) define o elemento econômico como sendo o conjunto de atividades produtivas capazes de serem rentáveis ao longo do tempo, preocupadas com a qualidade de vida. O mesmo autor considera que o fator social é alcançado quando há um desenvolvimento compatível das atividades com os valores culturais e expectativas das sociedades. Percebe-se a necessidade da interação das três variáveis citadas para haver um efetivo desenvolvimento sustentável e isso vale também para as propriedades familiares rurais.

Para a FAO (Organização das Nações Unidas para Agricultura e Alimentação), o conceito de agricultura sustentável se constitui no

manejo e a conservação da base de recursos naturais, e a orientação da mudança tecnológica e institucional, de maneira a assegurar a obtenção e a satisfação contínua das necessidades humanas para as gerações presentes e futuras. Tal desenvolvimento susten-tável (na agricultura, na exploração florestal, na pesca) resulta na conservação do solo, da água e dos recursos genéticos animais e vegetais, além de não degradar o ambiente, ser tecnicamente apropriado, economicamente viável e socialmente aceitável. (FAO, 1992 apud VEIGA, 1994, p. 22).

Ehlers (1994) apresenta alguns itens importantes na definição e que integram o conceito de sustentabilidade, como a manutenção em longo prazo dos recursos naturais e da produtividade agrícola; a preocupação com o mínimo de impactos adversos ao ambiente; a obtenção de retornos adequados e razoáveis aos produtores; bem como a otimização da produção das culturas com o mínimo de imputs químicos; a satisfação das necessidades humanas de alimentos e renda. Tudo isso em prol do atendimento das necessidades sociais das famílias e das comunidades rurais.

Isto posto, percebe-se que é necessária a interação harmônica dos três elementos, ambiental, econômico e social, para que efetivamente se alcance a sustentabilidade. Nesse sentido, é importante que a taxa de utilização dos recursos naturais não seja superior à capacidade regenerativa dos recursos naturais exauríveis. Faz-se necessário, também, que as atividades rurais sejam desenvolvidas de forma socialmente justa, ecologicamente correta, além de serem economicamente viáveis.

\section{METODOLOGIA}

A pesquisa, de acordo com Lakatos e Marconi $(2005$, p. 157), pode ser definida como "um procedimento formal, com método de pensamento reflexivo, que requer um tratamento científico e se constitui no caminho para conhecer a realidade ou para descobrir verdades parciais". 
Esta pesquisa caracteriza-se como sendo de natureza qualitativa, por trabalhar com variáveis que expressam a opinião e a ideia sobre determinado fator que se deseja avaliar. Porém, para uma melhor interpretação de alguns fatores, a pesquisa também apresenta natureza quantitativa, pela necessidade do emprego de técnicas estatísticas, visando um tratamento mais adequado dos dados.

A pesquisa de natureza quantitativa caracteriza-se por apresentar propósito orientado pela necessidade de verificar hipóteses previamente formuladas e identificar a existência ou não de relações entre variáveis privilegiadas. O processo de coleta de dados prioriza números ou informações que possam ser quantificadas. Os dados coletados e processados são interpretados e analisados com os recursos oriundos da Estatística, e a preocupação central reside em testar a hipótese para validá-la ou não.

Quanto aos objetivos de se avaliar a percepção dos produtores em relação às práticas sustentáveis e à Legislação Ambiental Brasileira, além de identificar algumas práticas adotadas para este fim, a pesquisa caracteriza-se como descritiva.

Gil (2002, p. 42), cita que as pesquisas classificadas como descritivas

têm como objetivo primordial a descrição das características de determinada população ou fenômeno ou, então, o estabelecimento de relações entre variáveis [...] uma de suas características significativas está na utilização de técnicas padronizadas de coleta de dados, tais como o questionário e a observação sistemática.

Ao considerarem-se os procedimentos técnicos e metodológicos, este estudo configura-se como de levantamento. Nas palavras de Gil (2002, p. 50), "caracteriza-se pela interrogação direta das pessoas cujo comportamento se deseja conhecer". Como método auxiliar de obtenção de dados, o questionário também representa uma técnica de pesquisa que pode ser definido, de acordo com Lakatos e Marconi (2005, p. 203), como "um instrumento de coleta de dados, constituído por uma série ordenada de perguntas, que devem ser respondidas por escrito e sem a presença do entrevistador".

A aplicação do questionário ocorreu em três do total de nove distritos de Santa Maria, o que representa $33,33 \%$ do universo. Os distritos santa-marienses onde se realizou o levantamento dos dados a fim de se inferir sobre as práticas sustentáveis e a percepção sobre a legislação ambiental foram: Pains, São Valentim e Arroio Grande.

\section{RESULTADOS}

Os resultados obtidos com esta pesquisa indicam que a maioria dos produtores rurais componentes da amostra possui uma preocupação com a questão ambiental e adotam critérios de preservação do meio ambiente, embora em níveis diferentes. Visando melhor responder aos objetivos propostos, dividiu-se a apresentação dos resultados em percepção ambiental e práticas sustentáveis adotadas pelos 47 produtores de agricultura familiar entrevistados dos distritos supracitados.

\section{I Percepção ambiental dos produtores rurais}

Para atender ao objetivo de analisar a percepção dos produtores rurais quanto às práticas sustentáveis, analisou-se a importância atribuída por estes a fatores como avaliação ambiental e legislação ambiental vigente.

Constatou-se que $55,32 \%$ dos produtores consideram muito importante e $40,43 \%$ importante, a consideração do tema ambiental para a busca da sustentabilidade nas atividades de agricultura familiar. Juntos, representam $95,75 \%$ do total, evidenciando o quão acentuada é, na visão dos produtores, esta questão. Isto pode ser verificado na figura 2.

Salienta-se que estes resultados são corroborados pelos que foram obtidos no estudo realizado por Zancan et al. (2012). Os resultados do referido estudo permitiram evidenciar que a questão ambiental, na percepção da totalidade dos gestores das agroindústrias do município de Santa Maria/RS, foi avaliada como importante.

Quando questionados sobre a opinião relativa à legislação ambiental brasileira, 23,4\% consideraram-na muito rígida e $6,38 \%$, rígida. Já 29,79\% dos produtores rurais avaliaram-na como adequada e $27,66 \%$, branda. Ressalta-se que $12,77 \%$ dos produtores entrevistados não possuem opinião formada a respeito dos aspectos associados à legislação ambiental, especialmente os aplicáveis à atividade desenvolvida. Apesar das divergências nas respostas, 57,45\% classificaram a lei como apropriada ou que necessita de melhorias, principalmente quanto a sua clareza e divulgação, fato constatado nas justificativas às respostas $e$ representado na figura 3 .

O estudo também investigou, no que concerne aos aspectos relativos à legislação ambiental, o processo de fiscalização das atividades rurais 


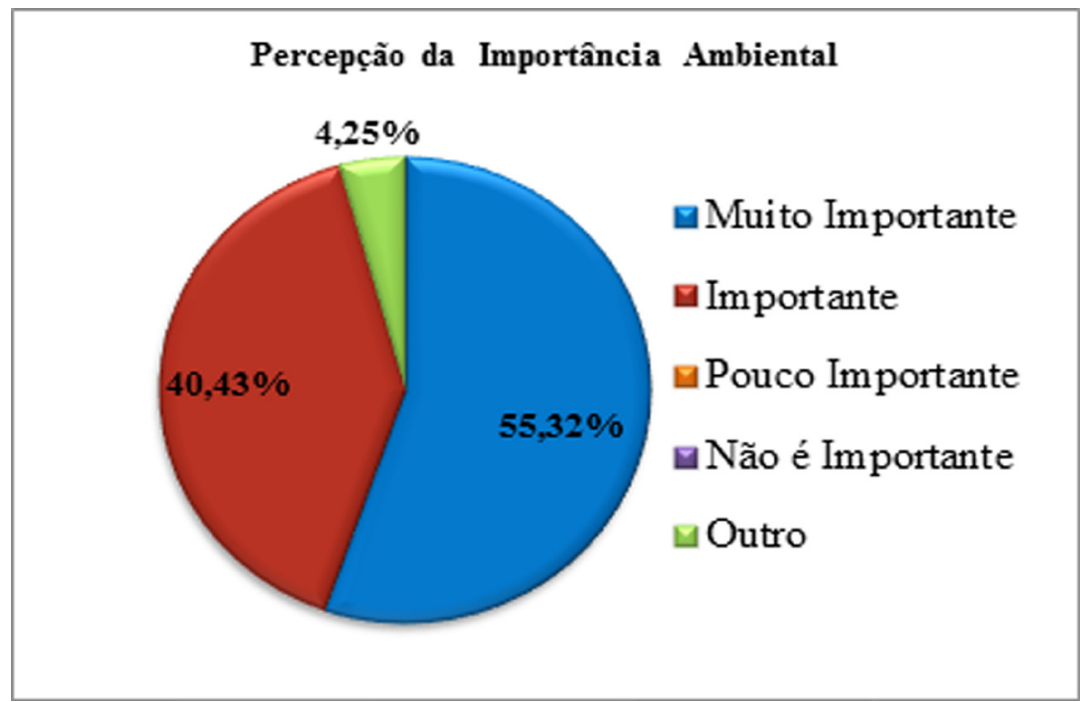

Figura 2 - Percepção dos produtores de agricultura familiar sobre a importância ambiental

Fonte: dados da pesquisa (2013).

pelos órgãos de controle ambiental.

Verificou-se que $80,85 \%$ das propriedades não sofreram nenhum tipo de fiscalização por parte dos órgãos ambientais. Apenas 17,02\% declararam terem sido vistoriados e 2,13\% não responderam. Este fato, atrelado à opinião de que a legislação é apropriada ou branda, pode ser um indício de que autuações não são necessárias ou não há eficiência na aplicação da lei junto às propriedades.

\subsection{Práticas sustentáveis na agricultura familiar}

A partir da análise de fatores como a prática da reciclagem, destinação de resíduos e demais medidas de caráter preservacionistas, buscou-se identificar e analisar as práticas de sustentabili- dade desenvolvidas pelos produtores dos distritos. Observou-se que $61,70 \%$ dos produtores desenvolvem medidas que visam à preservação ambiental como: preservação da mata ciliar, devolução de embalagens de agrotóxicos, bem como seu adequado manejo para evitar poluição da água e do solo. Entretanto, 29,79\% deles não desenvolvem tais medidas e $8,51 \%$ não responderam. A figura 4 evidencia os resultados analisados.

Em relação à reciclagem e/ou reaproveitamento de resíduos, onde os orgânicos são utilizados para adubação, e os inorgânicos são destinados aos pontos de coleta, constatou-se que apenas $48,94 \%$ dos produtores, que representam menos da metade da amostra, desenvolvem algumas dessas

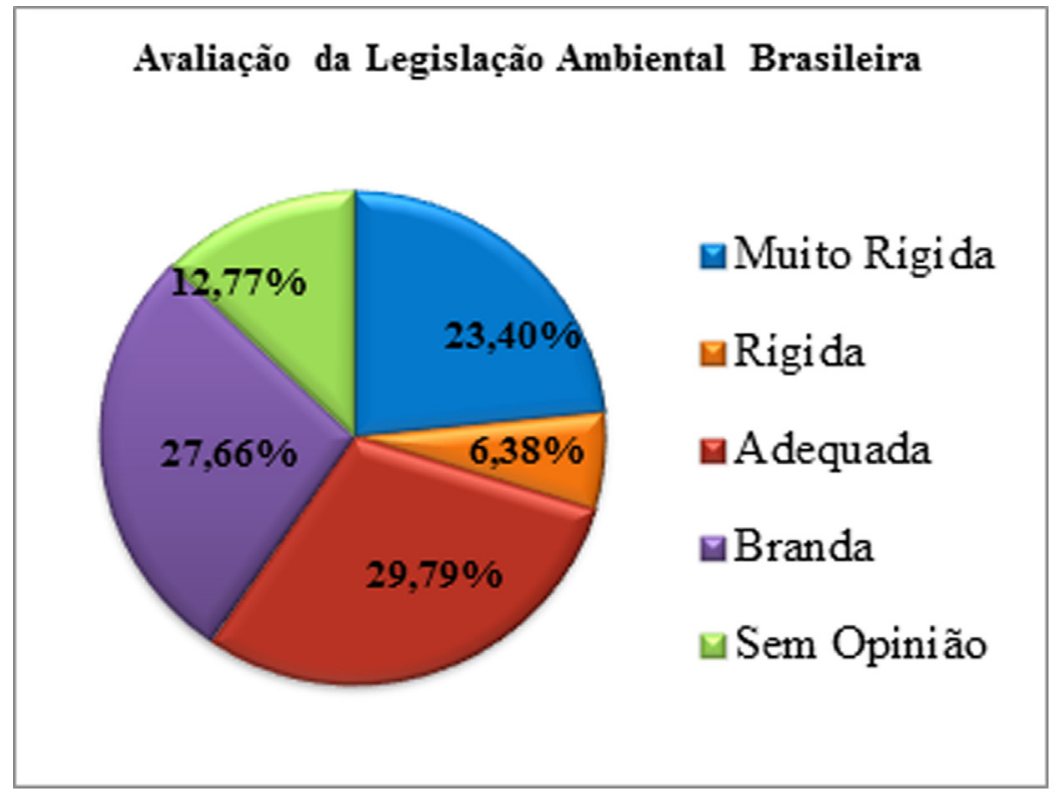

Figura 3 - Avaliação da legislação ambiental brasileira

Fonte: dados da pesquisa (2013). 


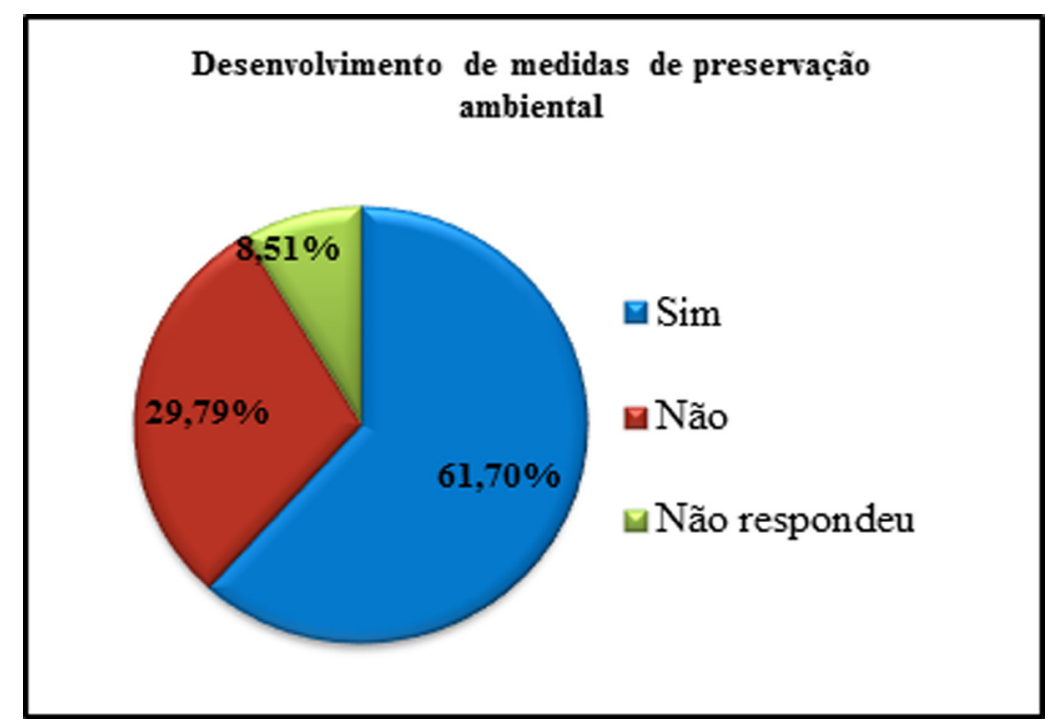

Figura 4 - Proporção de agricultores familiares que desenvolvem medidas de preservação ambiental Fonte: dados da pesquisa (2013).

práticas, enquanto que $42,55 \%$ afirmaram não implantar nenhuma medida. Além disso, 8,51\% não responderam à questão. Tais evidências podem ser verificadas na figura 5 .

Comparativamente aos resultados obtidos no estudo realizado por Zancan et al. (2012), a reutilização dos resíduos pelos produtores de agricultura familiar do município de Santa Maria/RS é de $48,94 \%$, sendo mais representativo do que o resultado obtido em termos de reaproveitamento junto às agroindústrias, onde apenas $32 \%$ efetivam tal prática.

A pesquisa também permitiu identificar que uma medida de preservação ambiental amplamente observada pelos produtores rurais consiste na adequada destinação do esgoto, tanto para fossa séptica como para fossa absorvente, pois $95,75 \%$ afirmaram que se utilizam destes métodos de descarte. Apenas 4,25\% ainda utilizam destinações inapropriadas, com lançamento dos resíduos em fluxos hídricos.

\section{CONSIDERAÇÕES FINAIS}

Este estudo objetivou avaliar a percepção dos produtores rurais de agricultura familiar dos distritos de Santa Maria/RS quanto à importân-

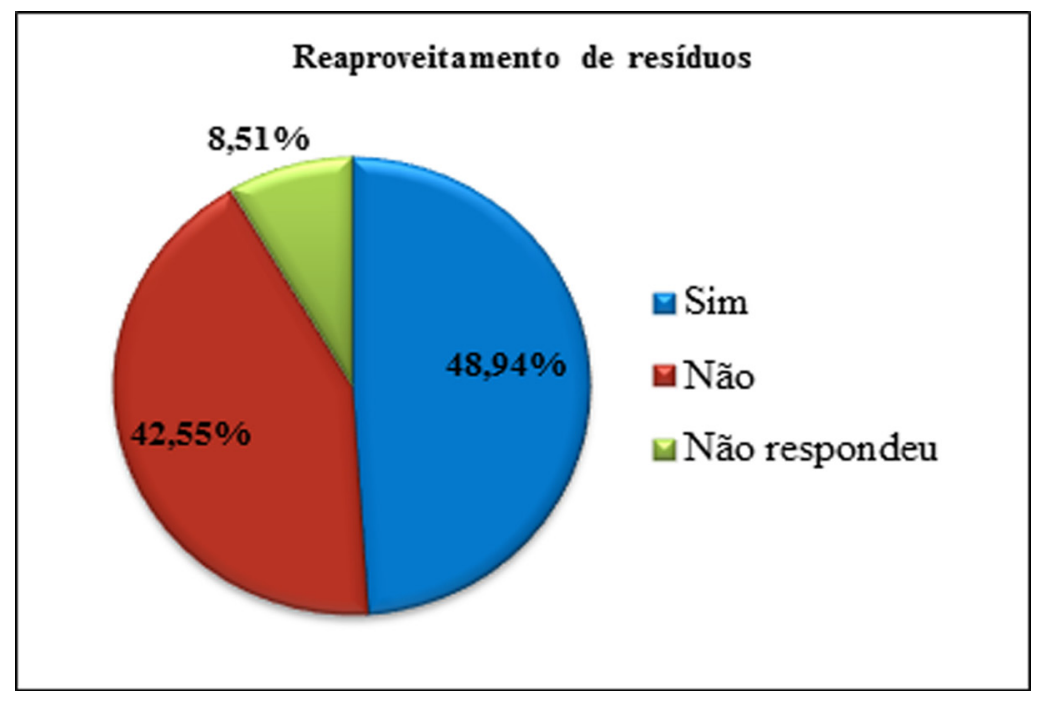

Figura 5 - Proporção de agricultores familiares que reaproveitam resíduos Fonte: dados da pesquisa (2013). 
cia da questão ambiental, sua avaliação quanto à legislação ambiental brasileira vigente, bem como identificar as práticas de sustentabilidade desenvolvidas em suas atividades.

A partir dos resultados obtidos, verificou-se que há uma contradição entre a importância alegada à questão ambiental pelos produtores de agricultura familiar e as práticas associadas à sustentabilidade desenvolvidas pelos mesmos, pois estas não acontecem na mesma proporção.

Analisando-se a percepção dos produtores, verificou-se a grande importância atribuída a questão ambiental, visto que $95,75 \%$ consideraram-na muito importante ou importante. O mais relevante é o fato de que nenhum dos produtores considerou pouco importante ou que tal questão não é importante.

Quanto à opinião sobre a legislação ambiental, a maioria dos produtores da amostra, ou seja, $57,45 \%$ consideraram-na adequada ou branda e outros $29,78 \%$ definiram-na como rígida ou muito rígida. No entanto, $12,77 \%$ não possuem opinião definida sobre o assunto. Essa divergência, atrelada ao fato de que $80,85 \%$ das propriedades não sofreram nenhum tipo de fiscalização ambiental, traz indícios de que provavelmente a legislação ambiental careça de clareza, tanto na sua divulgação como na aplicação, pelos órgãos fiscalizadores.

Considerando-se as práticas sustentáveis adotadas pelos produtores de agricultura familiar, percebeu-se que, apesar de $61,70 \%$ dos produtores afirmarem que desenvolvem medidas que visem à preservação ambiental, grande parte revelou não adotar nenhuma dessas práticas, correspondendo a $29,79 \%$ dos entrevistados. A reciclagem dos resíduos apresenta-se como a prática menos desenvolvida, visto que $48,94 \%$ reutilizam resíduos, enquanto que $42,55 \%$ não realizam a destinação correta de resíduos da sua propriedade. Uma coleta efetiva por parte dos órgãos públicos proporcionaria uma melhor destinação dos resíduos inorgânicos.

Uma prática que revelou possuir efetividade, nas propriedades de agricultura familiar pesquisadas, foi a destinação do esgoto, pois somente $4,25 \%$ ainda utilizam-se de meios inapropriados.

Nesta pesquisa, constatou-se que, apesar de atribuírem grande relevância à questão da sustentabilidade, muitos produtores não desenvolvem medidas de preservação ambiental, além de não haver uma preocupação com o adequado destino aos resíduos da propriedade.

Pode-se inferir que os produtores não estão desenvolvendo suas atividades de maneira plenamente sustentável, visto que um de seus pilares, o ambiental, apresenta inadequações. Isto acarreta um desequilíbrio na interação das variáveis que compõem o desenvolvimento sustentável. Não desenvolvendo atividades que visem à preservação ambiental e descumprindo a legislação, as atividades podem gerar possíveis impactos econômicos negativos para a propriedade e, consequentemente, sobre a dimensão social.

Para estudos futuros, sugere-se identificar e analisar quais as práticas sustentáveis de caráter social e econômico que são internalizadas no desenvolvimento das atividades rurais do município de Santa Maria/RS.

\section{REFERÊNCIAS}

AFONSO, C. M. Sustentabilidade: caminho ou utopia? São Paulo: Annablume, 2006.

BARBIERI, J. C.; CAJAZEIRA, J. E. R. Responsabilidade social empresarial e empresa sustentável: da teoria à prática. São Paulo: Atlas, 2009.

BERRY, M. A.; RONDINELLI, D. A. Proactive corporate environment management: a new industrial revolution. The Academy of Management Executive, Briarcliff Manor, v. 12, n. 2, p. 38, May 1998.

BRASIL. Lei n. 4.504, de 30 de novembro de 1964. Esta Lei regula os direitos e obrigações concernentes aos bens imóveis rurais, para os fins de execução da Reforma Agrária e promoção da Política Agrícola. Diário Oficial [da] República Federativa do Brasil, Brasília, DF, 30 nov. 1964. Disponível em: <http:// www.planalto.gov.br/ccivil_03/leis/14504.htm>. Acesso em: 23 jun. 2013.

BRASIL. Lei n. 11.326, de 24 de julho de 2006. Estabelece as diretrizes para a formulação da Política Nacional da Agricultura Familiar e Empreendimentos Familiares Rurais. Diário Oficial [da] República Federativa do Brasil, Brasília, DF, 24 jul. 2006. Disponível em: <http://www.planalto.gov.br/ ccivil_03/_ato2004-2006/2006/lei/111326.htm>. Acesso em: 24 jun. 2013.

BUAINAIN, A. M. Agricultura familiar, agroecologia e desenvolvimento sustentável: questões para debate. Brasília: IICA, 2006.

BUAINAIN, A. M.; ROMEIRO, A. A agricultura familiar no Brasil: agricultura familiar e sistemas de produção. Brasília, DF: Incra, 2000. 62 p. Projeto: 


\section{UTF/BRA/051/BRA.}

CREPALDI. S. A. Contabilidade rural: uma abordagem decisorial. 3. ed. revista, atualizada e ampliada. São Paulo: Atlas, 2005.

EHLERS, E. M. O que se entende por agricultura sustentável? 1994. 165 f. Dissertação (Mestrado em Ciência Ambiental) $\square$ Universidade de São Paulo, São Paulo, 1994. Disponível em: <http://www.teses. usp.br/teses/disponiveis/90/90131/tde-25112011091132/>. Acesso em: 28 jun. 2013.

GIL, A. C. Como elaborar projetos de pesquisa. 4. ed. São Paulo: Atlas, 2002.

\section{INSTITUTO BRASILEIRO DE GEOGRAFIA E ESTATÍSTICA. IBGE. Censo agropecuário bra- sileiro 2006. Brasília/DF, 2006. Disponível em: $<$ http://biblioteca.ibge.gov.br/visualizacao/perio- dicos/50/agro_2006_agricultura_familiar.pdf>. Acesso em: 25 jun. 2013.}

\section{INSTITUTO BRASILEIRO DE GEOGRAFIA E} ESTATÍSTICA. IBGE. Censo populacional 2010. Brasília/DF, 2010. Disponível em: <http://www. censo2010.ibge.gov.br/sinopse/index.php?dados $=8>$. Acesso em: 25 jun. 2013.

LAKATOS, E. M.; MARCONI, M. A. Fundamentos de metodologia científica. 6. ed. São Paulo: Atlas, 2005.

LIMA, L. M. Q. Lixo: tratamento e biorremediação. 3. ed. São Paulo: Hemus, 1995.

MICHAUD, R. Relatório final de missão em administração rural. Embrater: Brasília, 1989. 71 p.

PAULUS, G.; SCHLINDWEIN, S. L. Agricultura sustentável ou (re)construção do significado de agricultura? Agroecologia e Desenvolvimento Sustentável, Porto Alegre, v. 2, n. 3, p. 44-51, 2001.

PETTER, R. L. As múltiplas expressões da sustentabilidade: a realidade regional do Corede da produção no Estado do Rio Grande do Sul. 2002. 160 f. Dissertação (Mestrado em Desenvolvimento Rural)-Universidade Federal do Rio Grande do Sul, Porto Alegre, 2002. Disponível em: <http://hdl.handle.net/10183/2623> Acesso em: 20 jun. 2013.

TINOCO, J. E. P.; KRAEMER, M. E. P. Contabilidade e gestão ambiental. São Paulo: Atlas, 2004.
VEIGA, J. E. Problemas da transição à agricultura sustentável. In: VEIGA, J. E. Agricultura Sustentável, São Paulo: IPE/USP, v. 24, p. 5-29, 1994.

(Coleção Estudos Econômicos).

WANDERLEY, M. N. B. O agricultor familiar no Brasil: um ator social na construção do futuro. In: PETERSEN, P. (Org.). Agricultura familiar camponesa na construção do futuro. Rio de Janeiro: AS-PTA, 2009. Cap. 2, p. 33-45.

ZANCAN, F. et al. Diagnóstico ambiental das atividades agroindustriais de Santa Maria. Santa Maria, 2012. Disponível em: <http://ecoinovar.com. $\mathrm{br} / \mathrm{cd} /$ artigos/ECO028.pdf>. Acesso em: 30 jun. 2013. 